\title{
Urban planning objects of protection as a component of the system of protection of the world heritage object
}

\author{
Aleksei Mikhailov,"* \\ ${ }^{1}$ Saint-Petersburg State University of Architecture and Civil Engineering, Saint-Petersburg, Russia
}

\begin{abstract}
The paper is devoted to research of scientific and methodological approaches to the definition of urban planning objects of protection. Attention is paid to individual objects of cultural heritage and the totality of such objects united in ensembles, as well as a significant area and complexity of the world cultural heritage site "Historical center of Saint-Petersburg and related groups of monuments". Typical examples are considered: Kirov Department Store and factory-kitchen, G. F. Voldt's Summer house, Estate of E. I. Lopukhina (Levashovy's, Vyazemski's) "Aspen Grove".
\end{abstract}

\section{Introduction}

Many people were searching for ways to describe and convey the essence of the historical city. Writers and poets search for it through artistic images, delighting us with a variety of narrative plots. Musicians search for harmony in the urban structure and transmit it through music. Artists do not spare the colors and skill of putting together a variety of components grandiose paintings or vice versa delve into the details admiring them. The research is an architect, especially the one whose task is to find the best way to ensure the preservation of historical urban architectural and space planning characteristics, first of all must understand the general idea, according to which the structure of the urban environment was formed and the factors that influenced it. Such an understanding will help to find a starting point for deeper research, in which, layer by layer, structurally and systematically it is necessary to separate from the general, the stable components that form the image of the urban historical landscape.

\section{Materials and methods}

In the practice of security zoning in Saint-Petersburg, such stable components had different names. Initially, all of them were combined as part of historically valuable city-forming elements or objects (HVCO). Then, when the Federal law "On the protection of cultural heritage objects" No 73-FZ allowed such a concept to be applied only to the components of the subject of protection of historical settlements, there was a transformation of the name,

* Corresponding author: kgiop501@yandex.ru 
but not the transformation of the essence of such components. Currently, they are divided into valuable elements of planning and landscape composition structures and are urban planning objects of protection (Mikhailov, 2017).

The detailed composition of the elements of the planning and landscape composition structure can be found in the law of Saint-Petersburg "On united zones for the protection of cultural heritage objects..." No 820-7 and the purpose of this publication is not to list them. The purpose is to analyze the ways and methods of their definition, especially since the author has done a lot of work both on the preparation of the last three editions of the city law on united protection zones, and scientific work on the systematization of subjects of protection of cultural heritage objects and methods of their definition (Sergey Sementsov, 2019).

When preparing the law on protection zones, the main method was the general-toparticular method. It made it possible to cover and describe the main characteristics of the urban landscape in a relatively short time and to establish a primary system of protection. (Galina Ptichnikova, 2016; Shuhana Shamsuddin, 2012; Hoda Zeayter, 2018; Ian J. W., 1980; Lodovica Valetti, 2019). Analyzing the components of the matter of the urban environment, the system of historical settlement in the modern territory of the city was identified (historically formed central part of the city, small towns, villages, including summer houses, historical localities and early ethnic settlements). These territorial formations connected roads that were not just transport highways, but also largely determined the further character of the city, as they were the axes of development. Then natural (relief, hydraulic system elements, etc.) and anthropogenic components were identified, which undoubtedly have a mutual influence on each other. Going from one, more general factor to another, more specific, from the historical system of open and closed spaces to their components: the planning system of streets, embankments, squares, green spaces, it was possible to gradually decipher and describe the genome of the city. A system of protection was built, including such elements of the landscape composition structure as panoramas, views, dominants, city silhouette, and others (Mikhailov, 2019).

\section{Results and discussion}

\subsection{Features of the methodological approach to the formation of a list of urban planning characteristics to be protected}

On the example of the preparation of the first editions of the united zones of protection of Saint- Petersburg, it seemed that the "trail is taken" and it remains only systematically and gradually, using the famous deductive method, decipher the historical urban landscape up to the smallest detail, thus creating a perfect system of protection. However, at some stage of research, the method stopped working. It became clear that further, more detailed description of the features of the historical landscape sections can't be provided only by studying the general laws and rules of urban development. It is necessary to study in detail individual historical ensembles and even objects of high historical and artistic significance and, therefore, are objects of cultural heritage.

To determine the relationship between the object and the environment is not a difficult task if there are qualitatively defined objects of protection, which must contain the entire list of features of the cultural heritage object, including its urban characteristics. However, having examined more than 3 thousand descriptions of heritage objects on the territory of Saint-Petersburg and other regions, it had to be admitted that when enough overall detailed description of the architectural features (interior and exterior), urban features are either not described at all or very superficially. 


\subsection{Examples and analysis of objects of protection of individual objects of cultural heritage of Saint-Petersburg}

For example, I would like to give a description of the subjects of protection for a number of objects.

1. Let's take, for example, a fairly recent subject of protection of the cultural heritage object of regional significance "Department Store and factory-kitchen", located at the address: 9, Stachek square, Litera A (KGIOP (Committee for state control, use and protection of historical and cultural monuments of Saint Petersburg) Order No 4-p, 2019), approved in 2019. The building was built in 1930 from reinforced concrete in the constructivist style with a free layout of architectural volumes and forms an ensemble of the Stachek square, the perimeter of which is formed by objects of Soviet architecture.

In order we will see detailed and high quality description: architectural solutions of facades, three-dimensional solution of the object (including a description of the nature of projections, bay windows and even yard space), a description of the structural system. A little more than a rough description of decorative finishes and space planning solutions and not a single word about the value of this object in the formation of the ensemble of the Stachek square, but who knows this square, he understands that in addition to the Narva Triumphal Arch, the underground Narvskaya and House of Culture named after Gaza, this object is the most important urban object of the square (The restoration project, 2001).

2. Another example is the "Summer House of G. F. Voldt", of the early XX century, located in the historical summer house development of the village of Olgino at the address: 16, Litera A, Khvoynaya street, Olgino village, at the corner of the block formed by Key Avenue and Khvoynaya street (KGIOP Order No 5-p, 2019).

George Ferdinandovich Voldt (self-taught inventor who worked at the factories of G.A. Lessner) purchased a plot of land in the 1910s and built it using innovative technology at that time, invented by himself from concrete stones of various textures and even colors (Mikhailov, 2001).

The most extensive description of the architectural and decorative solution of the facades of this building is supplemented by a less detailed description of the structural elements and a description of the three-dimensional solution of the building. And if the three-dimensional solution of the interiors virtually no attention, because of their lack of the same attention to urban characteristics, which include only the location of boundaries of the territory of object of cultural heritage, is puzzling, particularly in view of the sufficiently important urban location of the house. There is no description of the historical and cultural significance in the order, which consists not only in the application of an innovative method of producing concrete blocks, but also in the history of the self-taught inventor who realized his dream of building a house using his own technologies.

3. In the final example we wanted to consider larger and more complex object - "Estate of E. I. Lopukhina (Levashovy's, Vyazemski's) "Aspen Grove", located at: Saint Petersburg, Vyborgsky district, Pargolovo village, Osinovaya Roscha, which includes the palace, coach house, stable building, water tower, park with four lakes with a total area of about 57 hectares. It is a component of the world heritage site number 540-024 (Popular science publication "36", 2019).

The Aspen Grove estate is part of the system of suburban estate complexes. In 1777, the lands of the manor of Aspen Grove, previously owned by count F. A. Apraksin, were granted by Catherine II to Prince Potemkin. Catherine considered the main advantage of this place to be the beautiful views that opened from the Yukkovsky hill to Saint-Petersburg and its surroundings. (Murashova, 2008)

In 1782, Potemkin sold these lands to the State Department, and they became the property of the peasants of the Saint-Petersburg State chamber. In 1824, the owner of the estate became a major statesman of the times of Paul I and Alexander I, Prince Peter 
Vasilyevich Lopukhin. At this time, the architect V. I. Beretti designed and built a manor house, offices, greenhouses, park is landscaped, roads. This wooden manor house has existed for more than 160 years. The layout of the park has been preserved to this day. In 1848 the owner of the Aspen Grove was count Vasily Vasilyevich Levashov (Major General, prominent statesman, Chairman of the State council), whose descendants owned the estate until 1917. At the end of the XIX century, the territory of the estate began to be sold for summer houses. After 1917, an agricultural school was established on the estate. Later, the palace was used as a recreation center. In 1991, as a result of a fire, the manor house was lost. The manor park is basically preserved, although modern summer houses have appeared on its territory.

Analyzing the order of the KGIOP of 16.01.2015 № 10-16 (Order of the KGIOP, 2015), we see, as in other similar documents, a more and less detailed description of the threedimensional solution of each real estate object that is part of the estate, which does not analyze the features of its perception and perception of the surrounding area from it. The architectural and artistic solution of facades is described, and elements of the structural system are mentioned. The space-planning solution is most often described without unnecessary details, for example, the historical space-planning solution in the dimensions of capital walls. The section three-dimensional solution and space-planning solution of the territory indicates the composition of the ensemble and the historical location of buildings on the territory of the park; visual links between historical buildings (however, there is no graphic designation of important visual connection).

The park, if we can say so, was more fortunate. In the description of the threedimensional solution we find: the location of boundaries of the park; relief; the configuration of the area on the plan; composition of the object; the historic location, dimensions, configuration objects included in the architectural-artistic ensemble; composition and visual connection; artistic architectural and layout solution of the area; historical three-dimensional arrangement; three-dimensional decision combining techniques of regular and landscape parks (including the historic shaft with planting fir trees and a ditch along the Priozersky highway); the historical composition of the central part with a meadow and paths; historic decision of north central alley, alley plantings, landscape group, valuable old-growth trees; elements of drainage systems; tracing and material (macadam printed coated) tracks; species composition of plantations.

However, nowhere in the order will we find a description of the town-planning features and significance of the object located along important historical routes-the Vyborgskoe and Priozerskoe highways. Will not see the description and (or) schemes of visual connections both internal and propagating outside of the object, and do not understand the environment in which it is located, which led to a massive building site opposite the central historic core of the estate on the opposite side of the Priozerskoe highway and as a consequence destroyed the beautiful views, opened with Yukkovsky hills to Saint-Petersburg and its neighborhood favorite by Catherine.

\subsection{Reasoning}

Despite the justified perplexity of such inattention to the description of urban planning and three-dimensional characteristics of the object itself and its environment, without which the very meaning of the existence of the object is often greatly distorted or even lost, I would not call this deliberate connivance. Rather, we are talking about the established practice of defining the subjects of protection of cultural heritage objects in isolation from their urbanplanning significance for the historical environment and the significance of the environment itself for their harmonious existence. This work is currently transferred by the current legislation to the section of works aimed at preserving the historical environment as a 
whole, and consists in determining the protection zones of a separate cultural heritage object or groups of such objects or the subject of protection of a historical settlement.

In one of the papers devoted to the subject of protection of historical objects of landscape architecture and landscape art, it was already described the principle of threedimensional composition, when the author meaningfully lays in it various cross-border characteristics, the preservation of which depends on the state of the surrounding urban planning, landscape, hydrological and even ecological situation (of course, first of all, panoramas and views). Just as often, the role of the object in urban planning composition is no less important, and not only dominant, but also environmental. On the example of landscape objects, the importance of preserving the urban planning characteristics of the object, it's subjects of protection, is understood more clearly due to their significant territorial coverage and complex three-dimensional composition. However, such research should be carried out for each object and not at the stage of preparation of the project of protection zones, but when preparing the initial list of its valuable characteristics to be preserved in any planned activity, which according to Federal law No 73-FZ is the subject of protection of the cultural heritage object.

These gaps in the methodological approach to the preservation of the historical environment that has been adopted as a basis fully explain the observations that arise periodically with regard to the current regulatory system in Saint-Petersburg. The current law is primarily focused on the preservation of urban planning subjects of protection that define the identity of our city, including as a world cultural heritage object.

\subsection{Evolution of regulation of the preservation of the historical environment}

And yet, despite the fair criticism, we must admit that the current law on united zones for the protection of cultural heritage objects is a product of the evolutionary development of ideas about the preservation of the historical environment, including through its deeper study. It is the boundary of zones of protection of objects of cultural heritage, approved by the Decision of the Executive Committee of the Leningrad city Council of people's deputies from 30.12.88 No 1045 "About approval of the united borders of zones of protection of monuments of history and culture in the central districts of Leningrad" have become the basis of boundaries of the main component of the world heritage object. Although at the time of inclusion, the subject of protection of the world heritage object "Historical center of Leningrad and its surroundings", which in international terminology is characterized as an outstanding universal value of the object, was not defined, it's urban planning components were already protected by the regulation prescribed in Decision No 1045.

\section{Conclusions}

Thus, it can be stated with confidence that the main urban planning subjects of protection of the world cultural heritage site "Historical center of Saint-Petersburg and related groups of monuments" are currently defined in two documents. One normative legal act-the Law of SaintPetersburg from 19.01.2009 No 820-7, which has already been mentioned, and the second, so far draft, order of the Ministry of Culture of the Russian Federation on the approval of the borders and subject of protection of the historical settlement "Saint-Petersburg". However, their detail and objectification require improvement. And in addition to more in-depth study of the historical environment and landscape of the city the success of the development requirements for preservation of urban planning subjects of protection depends on right combination of different research methods, including a more detailed definition of subjects of protection of separate objects of cultural heritage. 
At the beginning of my work on the systematization of the methodology for determining the subjects of protection of cultural heritage, I was almost sure that the wrong approach to determining the zones of protection of cultural heritage objects is based largely on the characteristics of the historical environment surrounding the object. In connection with this opinion, I had the idea of writing a critical article on this, as it seemed to me, incongruity with the cheerful title "How I put my pants over my head, or the modern way of establishing protection zones for cultural heritage objects". However, after research, I have come to believe that both approaches are important, both from the general to the particular, and vice versa. This is the only way to get a reliable picture of all the components of the subject of protection, including urban planning, and to ensure the preservation of the original features of the historical city.

Author expresses gratitude to S.V. Sementsov, E.A. Kozyreva, N.V. Murashova, T.A. Slavina.

\section{References}

1. N.V. Murashova, L.P. Myslina, Noble estates of the Saint-Petersburg province. Vsevolozhsky district (181-202, Alaborg, 2008)

2. N. V. Mikhailov, Lakhta. Five centuries of history $(117,2001)$

3. KGIOP order № 4-p of 11.01.2019 "On approval of the subject of protection of the object of cultural heritage of regional significance Department Store and factorykitchen"

4. KGIOP order № 5-p of 11.01.2019 "On approval of the subject of protection of the object of cultural heritage of regional significance" Summer House of G. F. Voldt"

5. KGIOP order № 10-16 of 16.01.2015 "On approval of the subject of protection of the object of cultural heritage of regional significance" Estate of E. I. Lopukhina (Levashovy's, Vyazemski's) "Aspen Grove”

6. Project of restoration and adaptation of the object of cultural heritage of regional significance "Department Store and factory-kitchen", 11-27, Architectural Bureau "Foundry part 91", KGIOP archive, Saint-Petersburg (2001)

7. Popular science publication "36" "Historical center of Saint-Petersburg and related groups of monuments. Cultural route", 101, Papyrus, Saint-Petersburg (2019)

8. A.V. Mikhailov, International Research Journal, № 10 (64), 125-128, Yekaterinburg (2017)

9. A.V. Mikhailov, Bulletin of the Tomsk State University of Architecture and Construction, № 3, 20-37 (2019)

10. S. Sementsov, N. Akulova, Proceedings of the 2019 International Conference on Architecture: Heritage, Traditions and Innovations. Advances in Social Science, Education and Humanities Research, 324, 425-433, AtlantisPress (2019)

11. G. Ptichnikova, Procedia Engineering, 1652016, 1903-1910

12. Sh. Shamsuddin, A. B. Sulaiman, R. Ch. Amat, Social and Behavioral Sciences, 502012, 238-253

13. H. Zeayter, A. M. H. Mansour, HBRC Journal, 14, 3, 345-356 (2018)

14. J.W. Ian, Landscape Planning, 7, 2, 121-149 (1980)

15. L. Valetti, A. Pellegrino, Ch. Aghemo, Journal of Cultural Heritage (2019) 